\title{
Features of an electricity supply system based on variable input
}

\section{F. WAGNER}

Max-Planck-Institut für Plasmaphysik - Greifswald, Germany, EURATOM Association and Research Laboratory for Advanced Tokamak Physics

St. Petersburg State Polytechnic University - St. Petersburg, Russia

Summary. - In this paper we analyse and present the major features of electricity production being based predominantly on variable wind onshore and offshore and on photovoltaic generation. Actual data are taken from the German demand and supply situation in 2010. On this basis, the generation capacities are scaled to higher installed powers. The main purpose of the paper is to show characteristic trends and the mostly system oriented consequences of large-scale wind and solar use with fluctuating input.

\section{1. - Introduction}

The need and desire for energy will further grow because the Earth population will further grow and the per-capita energy use will continue increasing: A saturation of the population can only occur over decades; the increase in per-capita energy is driven by the large global differences in the individual availability of primary energy ranging from tens of $\mathrm{kW}$ to a few $100 \mathrm{~W}$ in terms of power. The success with new energy technologies will decide about the avoidance of societal frictions in possible periods of deficit and energy 
TABLE I. - Electricity sources in Germany in 2010 [4].

\begin{tabular}{|l|l|l|}
\hline Source & TWh & $\%$ \\
\hline Coal & 105.8 & 18 \\
\hline Lignite & 135.2 & 23 \\
\hline Nuclear & 135.2 & 23 \\
\hline Gas & 82.3 & 14 \\
\hline Wind onshore & 35.3 & 6 \\
\hline Photovoltaic & 11.8 & 5 \\
\hline Bio-mass & 29.4 & 3 \\
\hline Hydro electricity & 17.6 & 5 \\
\hline Oil, pump storage, others & 29.4 & 1 \\
\hline waste & 5.9 & 2 \\
\hline
\end{tabular}

paucity and the prevention of the ongoing environmental damages by the replacement of fossil fuels.

There are only three paths to a sustainable energy supply system — fission on the basis of breeders, fusion, and renewable energies (REs) in their different forms of occurrence [1]. In this paper we analyse the major characteristics of an electricity supply system which is predominantly based on RE. We do this with the example of Germany because of the rapid deployment of renewable energies. Germany will soon demonstrate the pros and cons of a rapid technology change for an essential commodity of the economy like electricity and it provides an attractive basis for a forward-looking analysis $\left({ }^{1}\right)$.

\section{2. - Starting data of 2010}

Modelling of characteristics of the electricity supply system for Germany with increasing contributions of the RE forms wind (on and offshore, $W_{\text {on }}$ and $W_{\text {off }}$ ) and photovoltaic (PV) power has been studied on the basis of available data of 2010. The 2010 data are publicly available for demand, onshore wind and PV. For offshore wind power, they had to be constructed from wind velocity measurement scaled to the offshore wind energy gained from the Alpha Ventus wind power park. The construction and details of the data set are described in the appendix.

In 2010, the net electricity production in Germany of $588 \mathrm{TWh}$ originates from the different sources according to table I.

The fossil fuel fraction is about $55 \%$. The $35.3 \mathrm{TWh}$ from onshore wind were produced by $27.2 \mathrm{GW}$ installed wind power and correspond to about $1300 \mathrm{~h}$ at full load (full load hours, flh, = harvested annual electrical energy/installed power) or, equivalently, to

$\left.{ }^{1}\right)$ A more detailed report is available under F. Wagner, IPP report 18/1, Sept. 2012. 


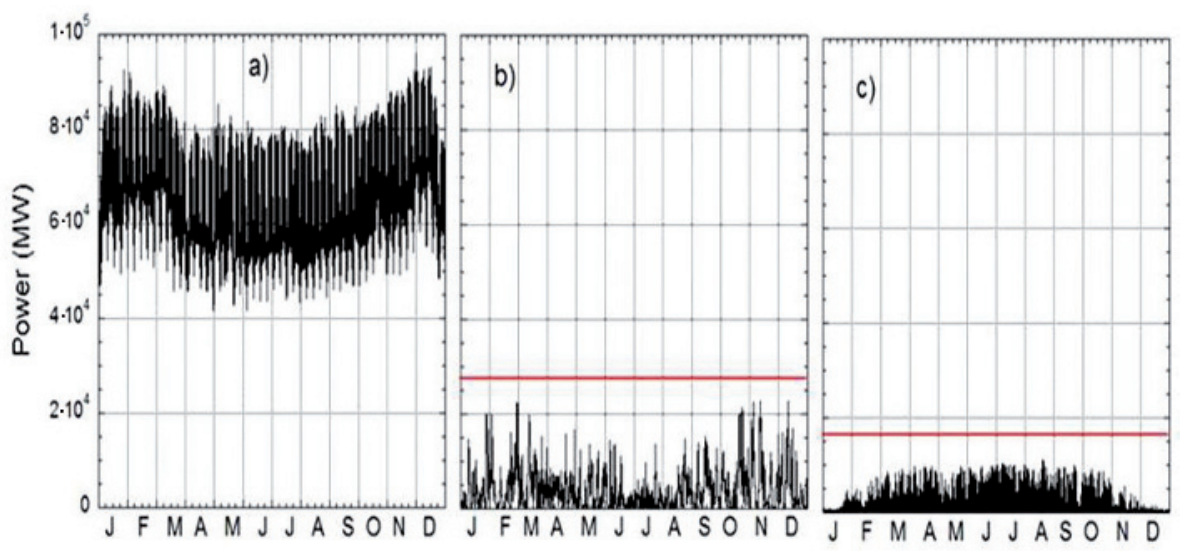

Fig. 1. - a) Variation of the load during 2010; b) onshore wind power in 2010; the red line denotes the installed wind power; c) PV power in 2010 but for constant installed power of $16.8 \mathrm{GW}$ (red line) correcting the strong build-up of PV systems through the year.

a capacity factor (or availability factor, $\mathrm{cf}=\mathrm{flh} / 8760$ ) in the use of the installations of $15 \%$ (2010 was a low-wind year). The up scaled $13.4 \mathrm{TWh}$ from PV are based on $16.8 \mathrm{GW}$ installed PV power and correspond to about $800 \mathrm{~h}$ of full load or to a capacity factor of $9 \%$. The operation of the Alpha Ventus wind farm for a full year would have yielded $0.203 \mathrm{TWh}$ for the $60 \mathrm{MW}$ installed power. This corresponds to $3400 \mathrm{~h}$ at full load or a capacity factor of $39 \%$.

Figures 1 a) to c) depict the data base constructed from actual data of 2010 as described in the appendix. Plotted are a) the demand (load), b) the onshore wind power and c) the PV power in their temporal developments through the year 2010. The PV data have been corrected for constant installed power. The horizontal lines in fig. $1 \mathrm{~b}$ ) and c) represent the actually installed power levels, which are found to be larger than the power peaks in the data sets indicating a reduced average availability. Figure 1 shows both the weekly and the seasonal variation of the reduced load; the daily variation is not resolved.

Figure 2. plots the load, onshore wind, and, on top of it, the PV contributions for January and July 2010 from the data set of fig. 1 in more detail with the daily variation being resolved now. The demand is lower during the weekends; wind is erratic and larger in winter and spring. PV responds in a periodic form - clearly visible in July — with maxima coinciding with the load maxima around noon-time.

Figure 3 shows the duration curves for the load and the contributions from wind and PV for 2010. In this plot, the data are not ordered chronologically, but rather is the respective power (averaged over $15 \mathrm{~min}$ ) ordered in descending sequence. This diagram allows categorizing the different contributions into base-load, mid-load and peak-load. It also helps to see the impact of an increasing share of renewable energies onto the park of conventional systems. Curve 1 corresponds to the load of 2010; curve 2, which is 

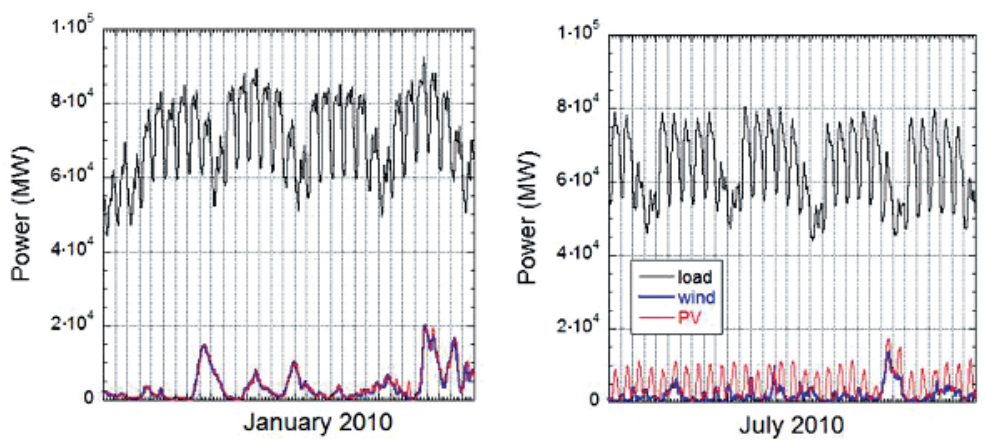

Fig. 2. - Load, onshore wind and, on top of it, PV are shown for January and July 2010.

dubbed "reduced load" in this paper, is obtained when the electricity contributions from hydro, storage and waste are subtracted; curve 3 represents the load after wind and PV contributions are subtracted (residual load).

Curve 4 and 5 are the duration curves of wind and PV, respectively. The horizontal line and the area beneath denote the corresponding nuclear base-load contribution in 2010; the grey area corresponds to the production of fossil power stations with $\mathrm{CO}_{2}$ release. Curve 4 shows that wind blows nearly throughout the year, whereas PV contributes for about half a year because of nighttimes without delivery.

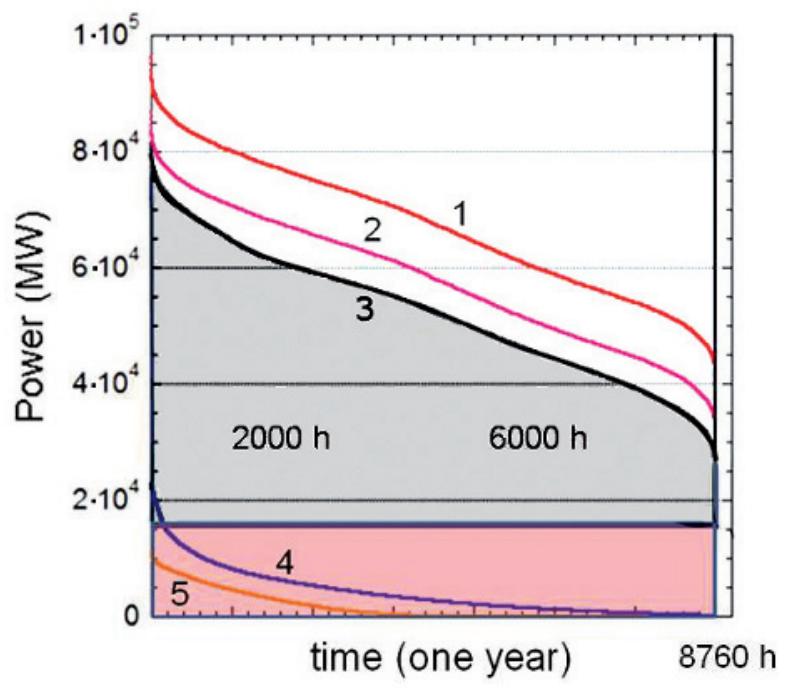

Fig. 3. - Demand-duration curve for 2010. 1 denotes the demand load; 2 the reduced load with hydro electricity and the ones from storage and waste subtracted; 3 denotes the residual load when wind (4) and PV (5) are additionally subtracted. The horizontal line denotes the nuclear power contribution; the grey area represents the contributions of fossil fuel power plants. 


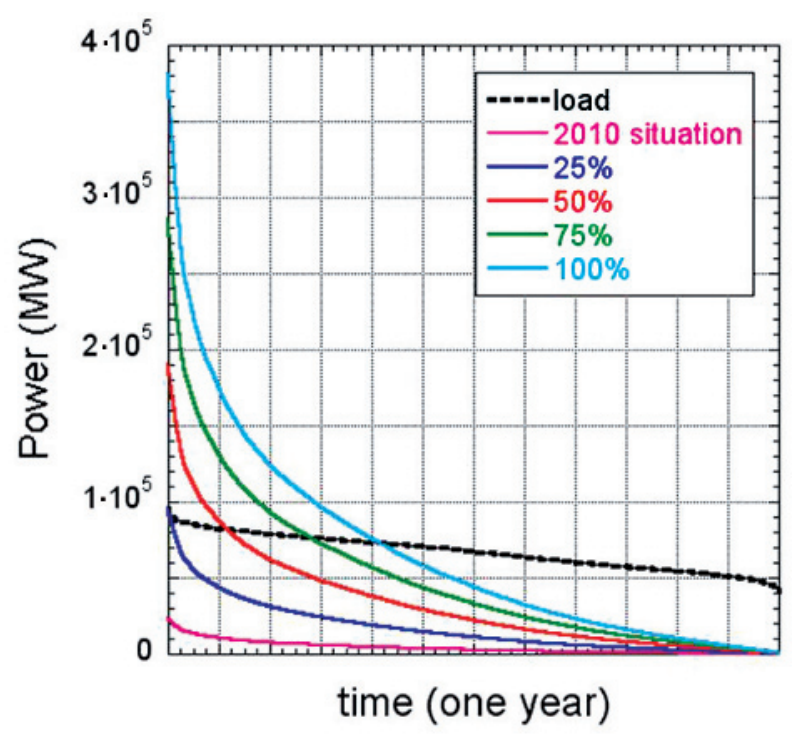

Fig. 4. - Duration curves representing the load (black) and onshore wind electricity (in colour) of 2010 along with scaled up values representing up to $100 \%$ of the average annual electricity demand.

Figure 3 points to a fundamental problem in the use of RE. The load curve is - seen from above - largely convex. The duration curves of wind and PV, however, are concave. Scaling to higher levels of wind and PV power capacity in order to ultimately match the annual energy consumption leads to large energy surpluses for extended periods. Figure 4 illustrates this consequence of the different duration curve curvatures in an exemplary way for onshore wind scaled up to increasing shares of the annual electricity production. For the case that onshore wind delivers the same amount of energy as the load demands ( $100 \%$ curve in fig. 4) the areas beneath this curve and the one beneath the load curve are the same. The temporal distributions of available power and demand, however, do not fit. The area where the $100 \%$ curve is above the load represents the surplus energy; the area with the load being above the $100 \%$ curve has to be delivered additionally by a back-up system satisfying the residual load. This $100 \%$ case is denoted in this paper as the "equal energy case".

Large RE power capacities have to be installed for substantial contributions to the annual energy demand. As a consequence, the peak power loads are greatly different for the surplus power and the back-up power cases. The power peaks dispatched into the grid can be as large as $400 \mathrm{GW}$, those which have to be handled as surplus power can be as large as $300 \mathrm{GW}$ for the "equal energy case". The peak powers in the back-up system do - of course - not surpass the level of the load. They can be lower to the extent the $\mathrm{RE}$ have contributions ensured throughout the year. These characteristics of variable supply are discussed in more detail in the following sections. 


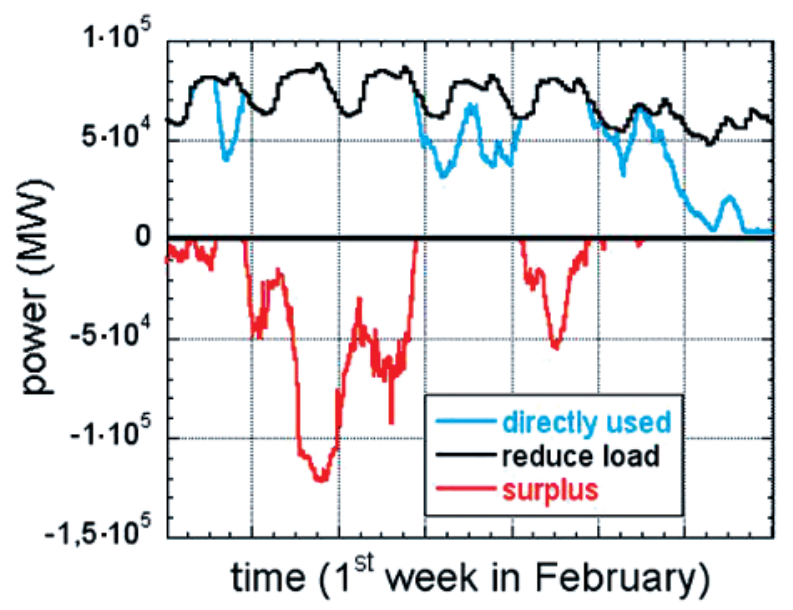

Fig. 5. - For the conditions of the first week in February 2010 the load (black), directly dispatched RE power (blue) and surplus power (red) are plotted. The RE part is scaled such that the annual energy of load and RE are the same ("equal energy case"). Wind and PV are mixed in the form of the "optimal mix" as discussed in sect. 4.

\section{3. - Scaling studies}

Whereas the net electricity production in 2010 is $588 \mathrm{TWh}$, the reference load value for the scaling studies of this paper is the "reduced load" of 562 TWh with the contributions from hydro, waste and storage electricity subtracted. We will not consider a bio-mass contribution assuming that the energy from bio-mass will be used in the future more for transportation, preferably for air traffic and less for electricity production. We further assume that the electricity consumption will not change expecting that effects of higher efficiency will be compensated by an expansion of the use of electricity e.g. in the field of mobility and smart supply systems or by technical measures, which will help reducing the primary energy consumption like a wide use of heat pumps. Nuclear energy and net electricity import are not considered.

For each time point $i$ in the data base the load, the on- and offshore wind power and the PV power are given. A positive difference between load and the sum of the three RE forms defines the back-up power at the time interval $i$. A negative difference (RE power $>$ load) gives the surplus power.

Figure 5 shows the different contributions for — as an example - the first week in February 2010 and shows the sharing between the different contributions - reduced load, directly used RE power and surplus power. As the powers do not agree for each moment, surplus energy needs to be collected and back-up power has to be available. The directly used power is limited by the load. The part surpassing the load adds to surplus power (negative). In periods where the RE contribution falls below the load, the surplus power is zero; the differences to the load are covered by the back-up system. The case shown in 


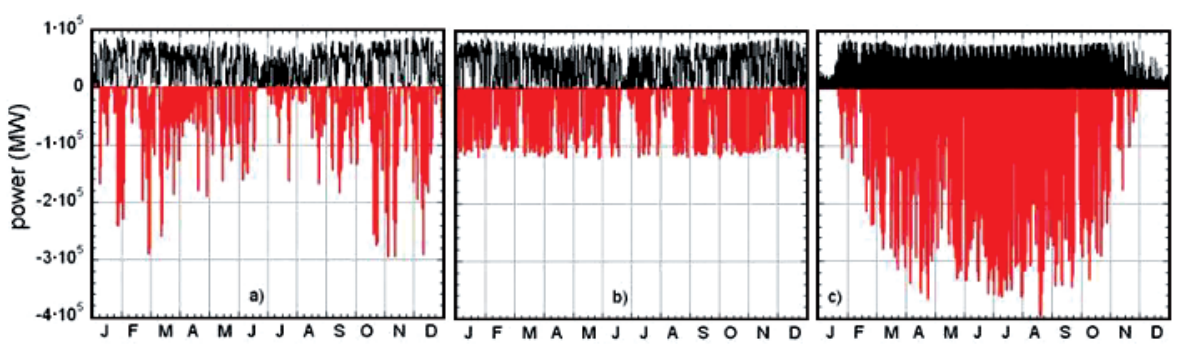

Fig. 6. - a) The scaled RE power is plotted for the case that the annual electricity production by $\mathrm{RE}$ is equal to the annual demand. Black represents the directly dispatched power up to the load as upper limit; red (negative) the surplus power. a) Onshore wind, b) offshore wind and c) PV.

fig. 5 is constructed such that the annual energies of load and RE sources are the same - the so-called "equal energy case". In this specific case the integral energies of the back-up system is equivalent to that of the surplus. The mix of RE energies in fig. 4 corresponds to the so-called "optimal mix" to be discussed in sect. 4.

3`1. RE produce $100 \%$ of the annual electricity. - Each of the RE supply forms has its own characteristics. In order to elucidate these features we first analyse and discuss them separately. The RE power in these cases is selected such that for each form separately the RE produces as much energy as the load integrally demands. The intention with the termination at this point is that the surplus power - if proper storage were available - would just be sufficient to compensate the primarily missing energy. In this case, no back-up power would be required any longer. Transfer and other process losses are not considered here.

Figure 6 a) to c) represent the power of onshore and offshore wind and of PV. Positive values denote the power directly contributing to satisfy the demand. The upper limit of the curves is determined by the load. What goes beyond the load represents the surplus power and is plotted negatively.

- Onshore wind power fluctuates with large amplitudes truly reflecting the variability of wind velocity. Onshore turbines rarely meet the conditions of strong winds where the wind turbines are switched to the constant output power mode.

- Opposite to this, offshore wind power is rather constant in amplitude because strong wind leads to prolonged phases with the turbines regulated at the rated output power point.

- PV power is again different because its power is periodic with daily peak contributions well matched to the high-demand periods. The cyclic behaviour of PV is reflected in the upper part of fig. $6 \mathrm{c}$ ) marking the demand peaks well. 

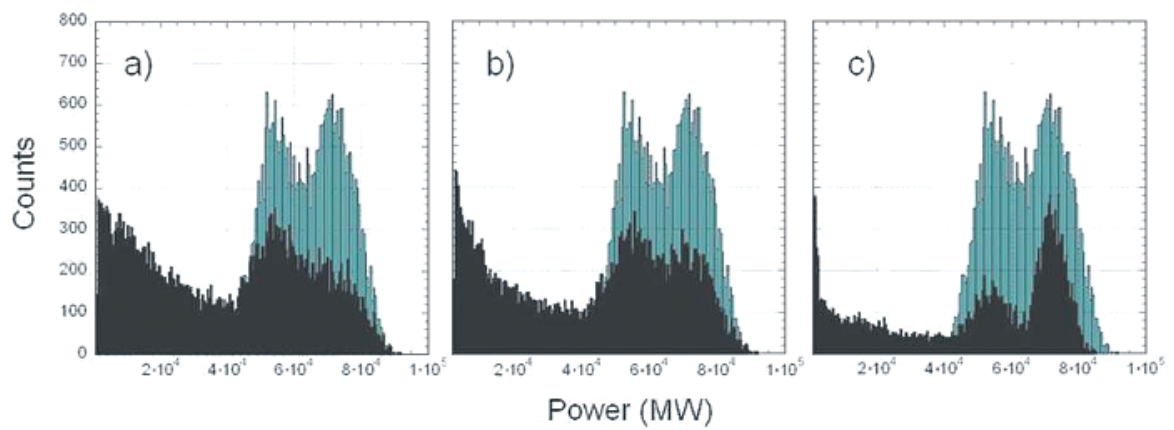

Fig. 7. - Histograms of the dispatched power (black) scaled to the $100 \%$ limit compared to the load of 2010 in each of the cases. a) Onshore wind; b) offshore wind; c) PV.

The two wind cases show lower power coverage of the load in summer whereas, reciprocally, the low coverage by $\mathrm{PV}$ is in the winter months. The surplus power peaks can be exceedingly high in the limit considered here ("equal energy case") and reach values frequently beyond $300 \mathrm{GW}$ in case of PV and onshore wind.

The histograms in fig. 7 plot the directly used power (black) produced by the three $\mathrm{RE}$ forms, which is delivered into the grid. It is compared with the load (green). The load distribution is characterized by two maxima, the higher-power one representing rather the load during the day, the lower-power one the load more during the night and weekends. The width of the two profiles is mostly given by the seasonal cycle. The $\mathrm{RE}$ powers show typically the concave distribution with the frequency of occurrence decreasing toward higher powers. The distribution of the directly used power increases, however, in the power range of the load because all power values falling into this interval but also all higher ones contribute to it. Because of the decay of the distribution toward higher powers, the "filling" of the power band of the load requires a large installed power so that specifically the excess power levels can be used to fill the load power band, which is offset from zero by a gap - the base load. The selectiveness of this process is obvious from fig. $7 \mathrm{c}$ ). In case of PV, the highest peaks are delivered during daytime. Therefore, the day-peak of the load is preferentially filled.

Both onshore and offshore wind produce powers up to the level of the demand curve. But the highest power peaks of the load occur in winter during daytime with little PV contribution. Therefore, this part of the load is - unlike the other cases - not covered in case of PV; a gap remains between the peak load and the PV distribution at the highest powers. For these periods, when exclusively PV is considered, the back-up system must be available up to the maximal required power.

The integrals of the directly used power distributions are not the same for the three cases (though the conditions RE energy = annual energy demand is the same). PV produces substantially more surplus energy than the other two cases - but in summer, which does not help the needs in winter. 
TABLE II. - The key characteristics of the three RE cases under the condition that the annual energy produced by the RE system is equal to the annual energy demand. The maximal power (identified as a lower limit to the installed power, because the average availability factor $<1$, see fig. 1), the directly used energy into the grid and the energy delivered by the back-up system which is equal to the surplus energy.

\begin{tabular}{|l|l|l|l|}
\hline & $\begin{array}{l}\text { Maximal power } \\
(\mathrm{GW})\end{array}$ & $\begin{array}{l}\text { Directly used energy } \\
(\mathrm{TWh})\end{array}$ & $\begin{array}{l}\text { Back-up = surplus energy } \\
(\mathrm{TWh})\end{array}$ \\
\hline Wind onshore & 365 & 344 & 218 \\
\hline Wind offshore & 165 & 344 & 218 \\
\hline PV & 463 & 214 & 348 \\
\hline
\end{tabular}

Table II shows the various key characteristics of the three RE forms under the limiting condition of the "equal energy case".

For the same annual energy, the necessary wind power to be installed is lower by a factor of more than 2 in case of offshore than onshore wind. The energy values for directly used and surplus/back-up energies, respectively, are the same for the wind cases because of a similar data structure representative of turbulent generation processes; they are different for PV with a more periodic spectral content. In a control run with random numbers replacing actual wind or PV data, the directly used, surpluss, and back-up power levels are equal at $281 \mathrm{TWh}$ adding up to the reduced load of $562 \mathrm{TWh}$.

Figure 8 a) to c) show the duration curves for the three cases considered. The black curve is the reduced load as defined above. The blue curves represent the RE power, which can directly be used. On- and offshore wind have contributions almost throughout the year. PV covers only about $50 \%$ of the year. The green curves denote the duration curve for the residual back-up power. Its contribution is strongly reduced compared to
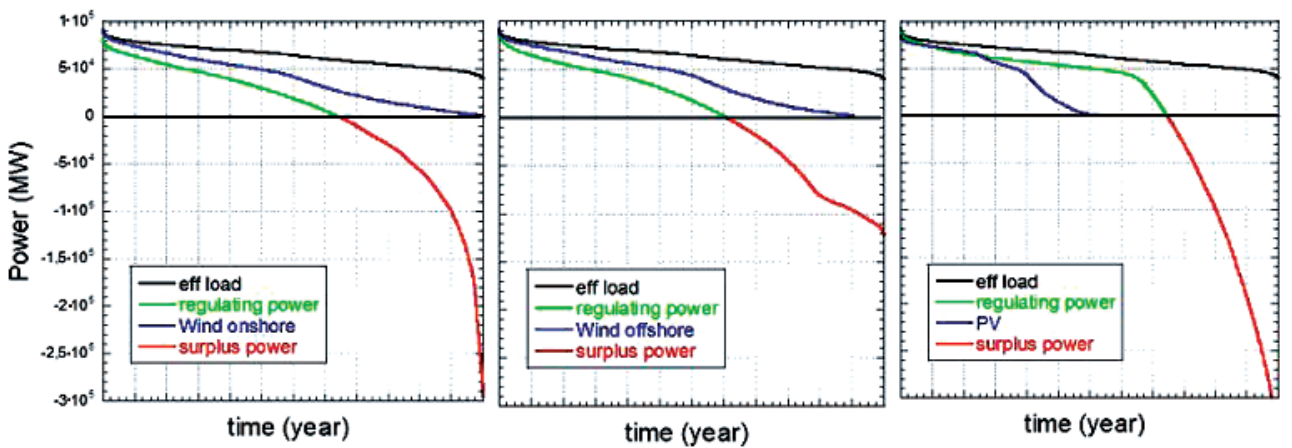

Fig. 8. - Demand-duration curves for a) onshore, b) offshore and c) PV. The black curve is the reduced load; the blue curve represents the $\mathrm{RE}$ contribution; the green curve the back-up power and the red branch the surplus power. 

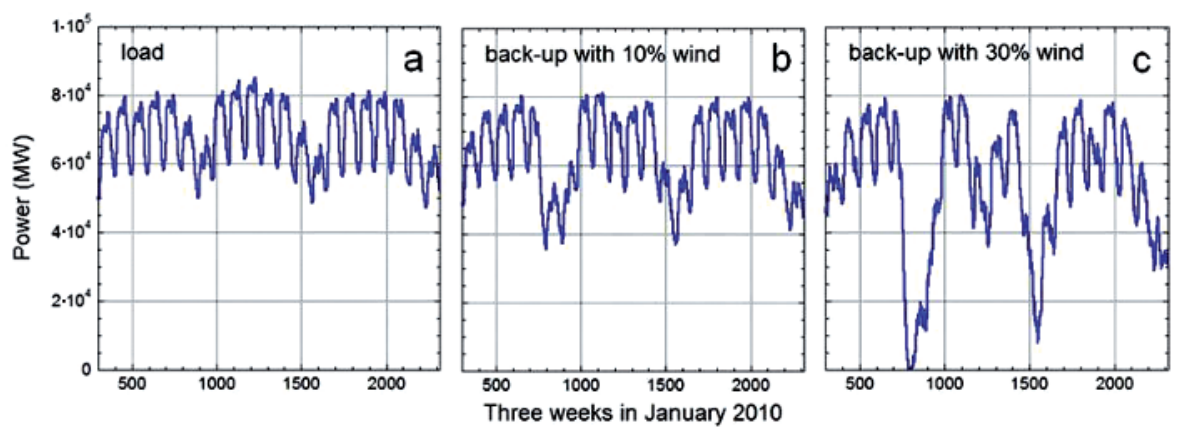

Fig. 9. - a) The load of the period from mid-February to mid-March 2010. Panels b) and c) represent the variation of the back-up systems when $10 \%$ or $30 \%$, respectively, is contributed by onshore wind.

the original situation without RE contribution (see table II); it loses the characteristics of a base load. The negative red curves represent the surplus power reproducing the already known effect that the surplus power is limited in case of offshore wind and extreme in case of PV.

3.2. Surplus power and operation mode of the back-up system. - With controllable sources, the power supply system responds to the periodic variation of the day/night cycle, the weekly and the seasonal variation: Electricity production is demand driven. The load variations are periodic and rather predictable. With RE the supply system splits up into the primary sources wind and PV and the secondary source, the back-up system based on thermal power for the near future covering the residual load. With increasing RE shares, the periodic variation of the back-up systems is changed to an erratic one reflecting the spectral character of the stochastic supply and to a lesser extent the periodic pattern of the load: Electricity production becomes supply driven.

Figure 9 shows the variation of the back-up power with onshore wind energy shares increasing from 0 to $30 \%$ of the annual demands. With $10 \%$ wind contribution the periodic pattern of the load is largely maintained. This reflects roughly the 2011 situation in Germany (wind and PV: $66 \mathrm{TWh}=11 \%$ of the demand [2]). With 30\% share, the periodic pattern is dissolved and the temporal characteristics of the residual power display chaotic traits.

In the following, we discuss the features in the transition from continuous to variable supply along power histograms. Figure 10 a) shows the power histogram of the reduced load. The peak and the base load powers are shown as vertical lines. The double-hump structure has already been discussed.

In the case that onshore wind contributes with $10 \%$ to the annual demand (fig. $10 \mathrm{~b}$ )) the main feature - the residual back-up power (black) distributed between base and peak load limits and separated from zero - is largely maintained. The lower level of the base-load is slightly shifted to lower power values. With $30 \%$ wind contribution to the 


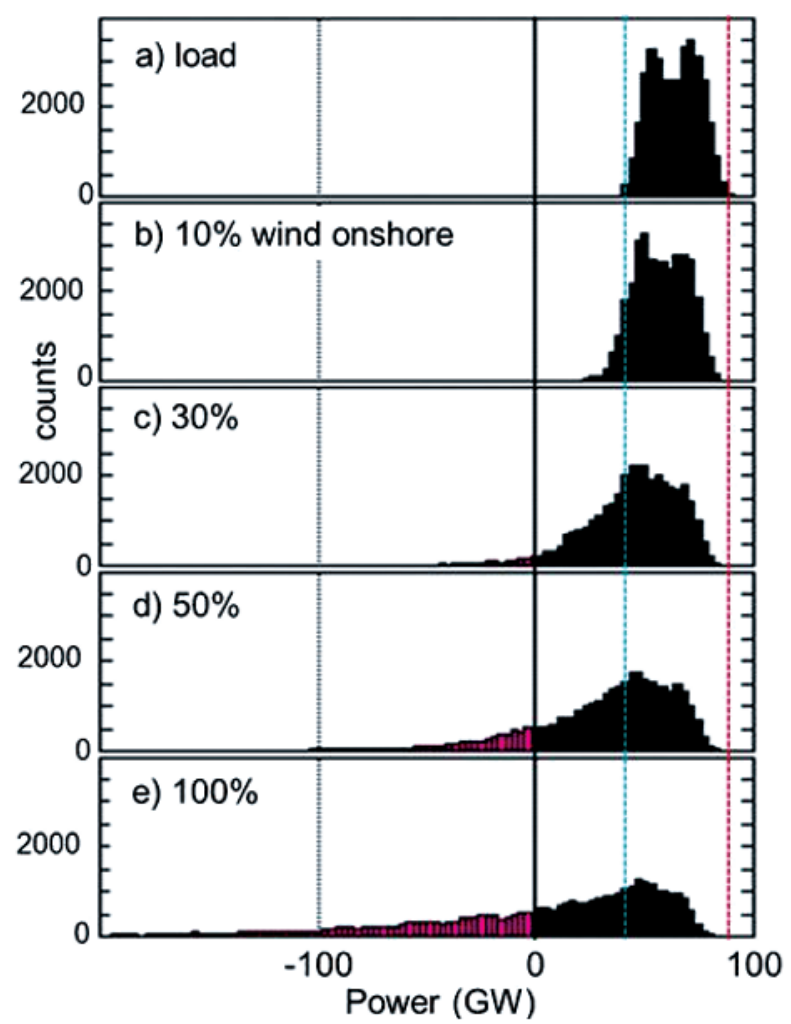

Fig. 10. - Histograms of the load and the power delivered by back-up systems (black) and of the surplus power (red) with onshore wind contributions increasing from $10 \%$ to $100 \%$ of the annually demanded electricity in 2010. The vertical lines denote the base-load (blue) and the peak-load (red) levels.

annual electricity (fig. 10 c)), the base load has disappeared and the back-up system has to supply all power levels from 0 to the maxima of the reduced load. In this case, already a distinct amount of surplus electricity is produced, which is plotted on the negative axis (red). This trend continues to larger wind electricity shares (fig. 10d) with surplus power levels reaching beyond $100 \mathrm{GW}$. Figure $10 \mathrm{e}$ ) represents the case where the annually produced wind energy (sum of directly used and surplus energies) is equivalent to the annual demand ("equal energy case"). Figure 10e) also shows the small shift of the power range of the back-up system away from the original peak load line to a slightly lower value. For this case, close to $10 \%$ of the installed back-up capacity can be saved owing to the installed wind system and its continuous contribution throughout the year (see also table III).

Table III lists the capacity factors of the back-up system defining its annual utilisation for varying contributions of the RE systems and also gives the maximal back-up power observed in the data set averaged over $15 \mathrm{~min}$. Given are the results for variable 
TABLE III. - Shown is the utilization of the back-up system (capacity factor) and its maximal power at variable RE contributions to the annual demand.

\begin{tabular}{|l|l|l|l|}
\hline $\begin{array}{l}\text { Energy source and } \\
\text { contribution }\end{array}$ & $\begin{array}{l}\text { RE contribution } \\
\text { (used+surplus) }\end{array}$ & $\begin{array}{l}\text { Capacity factor of } \\
\text { back-up system }\end{array}$ & $\begin{array}{l}\text { Maximal power of } \\
\text { back-up system (GW) }\end{array}$ \\
\hline & 0 & 0.70 & 92 \\
\hline Wind onshore & 10 & 0.67 & 86 \\
\hline Wind onshore & 30 & 0.53 & 85 \\
\hline Wind onshore & 50 & 0.43 & 84 \\
\hline Wind onshore & 100 & 0.30 & 83 \\
\hline Wind offshore & 100 & 0.29 & 87 \\
\hline PV & 100 & 0.43 & 92 \\
\hline
\end{tabular}

contributions of onshore wind and also for $100 \%$ energy from offshore wind or PV, respectively. For the "equal energy case" onshore and offshore wind reduces the back-up capacity factors to about $30 \%$. In case of PV, the back-up system is more frequently in use. As already shown in fig. 7, PV does not allow a reduction in installed back-up power — unlike wind electricity with a reduction from 92 to $83 \mathrm{GW}(-8 \%)$. The jump from $92 \mathrm{GW}$ installed power to $86 \mathrm{GW}$ with already $10 \%$ onshore wind is caused by the removal of peak load demands from the back-up system, which happens for about $50 \mathrm{~h}$ in the year. This effect may be a particularity of the wind situation in 2010 .

3·3. Summary of scaling studies. - In fig. 11 a) the produced RE electricity (directly used and surplus) is plotted against the maximal RE power in the data set of the respective scan for on- and offshore wind and PV. The relation is linear $\left({ }^{2}\right)$. Technical losses in production or transmission are neglected because they are not relevant for the considerations of this paper. The necessary installed power capacities are actually larger than the power values quoted here $\left(^{3}\right)$ by a factor of 1.2 for onshore wind or 1.5 for $\mathrm{PV}$, respectively. For the truly installed power and the corresponding capital costs for their implementation, the maximal power values of fig. 11 represent therefore lower limits.

The horizontal dotted line in fig. 11 a) corresponds to the reduced load of integrally $562 \mathrm{TWh}$, which has to be produced to meet the $588 \mathrm{TWh}$ net electricity target together with electricity from hydro and waste. The solid data points close to the origin represent energy and installed power of onshore wind (black squares), offshore wind (red square), and PV (blue square) at the end of 2010, and 2011 and as expected for 2012. These

$\left({ }^{2}\right)$ In reality, the relation is not linear rather bands over because in the process of increasing the installed power, less favorable locations have to be selected for RE production.

$\left(^{3}\right)$ E.g. in 2010, the maximal power of onshore wind in the data base was $22.8 \mathrm{GW}$ whereas the installed power was actually $27.2 \mathrm{GW}$ (see fig. 1); similarly, the maximal PV power in the data set of $11 \mathrm{GW}$ compares with $16.8 \mathrm{GW}$ installed power. 

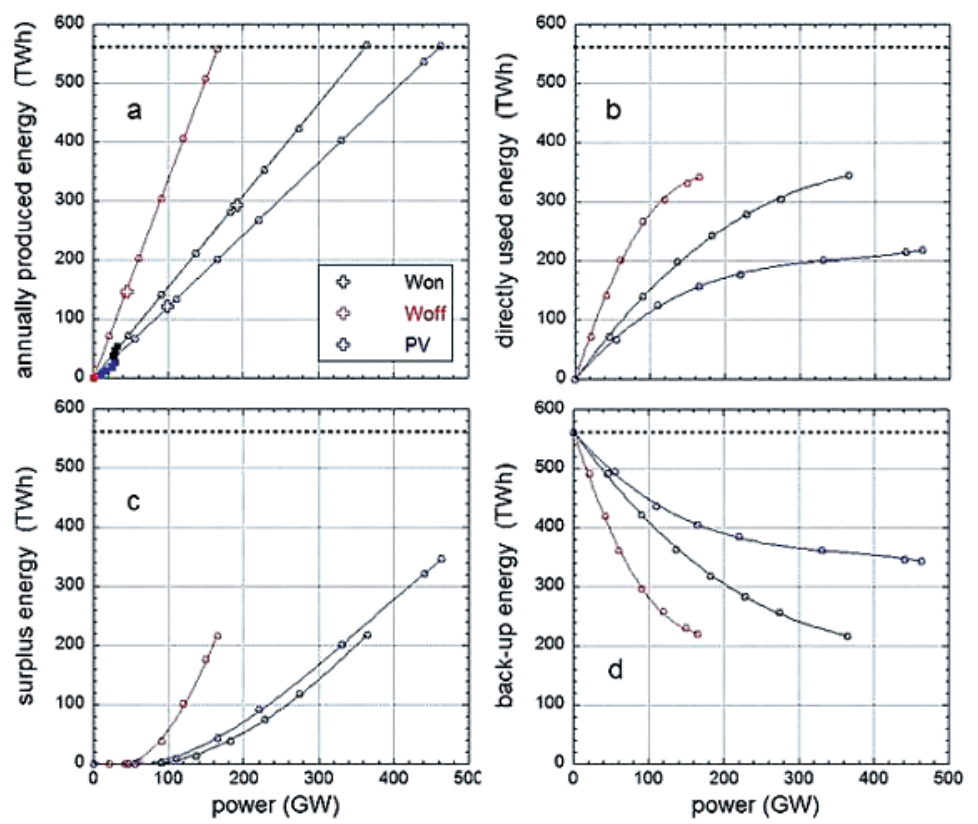

Fig. 11. - a) The produced energy against the maximal RE power in the data set (lower limit of the installed power) for on- and offshore wind and PV. The horizontal line represents the level of the reduced load in Germany in 2010. The squares close to the origin represent energy and installed power of onshore wind (black), offshore wind (red) and PV (blue) for 2010, 2011, and as expected for 2012. The open crosses represent the key data of the optimal mix of the RE system as described in sect. 4. b) directly used energy; c) surplus energy; d) back-up energy. The curves end when the total energy delivered by the RE systems is equal to the annual demand (see a)).

data points indicate the still infant nature of the RE deployment in Germany in spite of tremendous efforts. The open crosses indicate the locations of the three RE components in case of the optimal mix as described in sect. 4. All curves in fig. 11 end when the energy produced by RE agrees with the annual demand - at the conditions of the "equal energy case" (e.g., see fig. 11a)).

Figure $11 \mathrm{~b}$ ) plots the annually produced energy, which is directly used for the three systems under consideration against the maximal power occurring in the data base. Figure $11 \mathrm{c}$ ) shows the annual surplus energy and finally, in fig. $11 \mathrm{~d}$ ) the energy of the back-up system is plotted.

The slopes in fig. 11 a) correspond to the annual full load hours which are $1550 \mathrm{~h}$ (wind on), $3385 \mathrm{~h}$ (wind off), and $1200 \mathrm{~h}$ (PV). The values are too high because the maximal power in the data set is smaller than the actually installed power (see footnote 3 ). Particularly, the actual full load hours of PV is closer to $900 \mathrm{~h}$ when the actually installed power is used as reference. 
The directly used energy of fig. 11 b) shows the tendency to saturate. This effect is specifically distinct for PV. The non-linear elements causing the saturation are the periods without RE electricity production irrespective of the installed power - wind velocity below the cut-in level or the nights in case of PV. All of the three RE forms stay well below the reduced load (dotted line in fig. 11) for the conditions considered here.

Owing to their concave power spectrum (e.g. see fig. 4) RE systems produce large amounts of excess power (see fig. $11 \mathrm{c}$ ), which cannot be accommodated within the national grid without storage. PV produces the largest amount of surplus power.

The energy delivered by the back-up system for the three RE cases considered deceases with increasing RE share (see fig. 11d). This dependence corresponds to the desired objectives in the use of RE. Back-up power is required up to the "equal energy case" and beyond. An exclusive PV system would necessitate the largest thermal power back-up system.

In conclusion, without storage, offshore wind as the "best" RE electricity source produces about $50 \%$ of the annual load with about twice the presently installed conventional thermal power. The other extreme is PV, which produces with close to $500 \mathrm{GW}$ installed power only about $1 / 3$ of the annual electricity.

\section{4. - Optimal mix between wind and PV installations}

The averaged load curve has a maximum in winter and a minimum in summer. This is also the case for wind electricity, which helps to match the seasonal cycle and is contrary to photovoltaic electricity production, which has a minimum in winter (see fig. 1). On the other hand, photovoltaic electricity is produced during the day when the demand is highest. Therefore, wind has a good annual and PV a good daily match to the load curve. The consequence is that there is an optimal mix for these two renewable energy forms. We define the optimum as the proper mix of wind and PV power, which minimizes the demand of back-up power (and therefore the amount of $\mathrm{CO}_{2}$ production as long as the back-up system is based on fossil fuels). We further assume that offshore wind produces $1 / 3$ of the wind energy.

Figure 12 plots the annually produced energy of the back-up systems normalized to the reduced load against the PV energy production also normalized to the reduced load. Parameter of the set of curves is the total contribution of RE also normalized to the reduced load. The curves show a minimum, which moves to larger PV contributions when the share of RE increases. The curves do not represent a symmetric case for wind and PV. The wind-only case is not much above the minimum whereas the PV-only case requires much more back-up contributions.

In the "equal energy case" the optimal PV contribution to the annual demand is $22 \%$; in case of $37.5 \%$ RE share this value drops to $10 \%$. However, for a $25 \%$ share and below, the ratio of wind to PV does not affect much the level of back-up power. Though the share of PV increases with the RE contribution under optimal mix conditions, the ratio of PV to wind decreases from about 0.5 at $37.5 \% \mathrm{RE}$ share to 0.27 for $100 \% \mathrm{RE}$ share. The ratio of offshore to onshore wind is found not to change much the results of fig. 12 . 


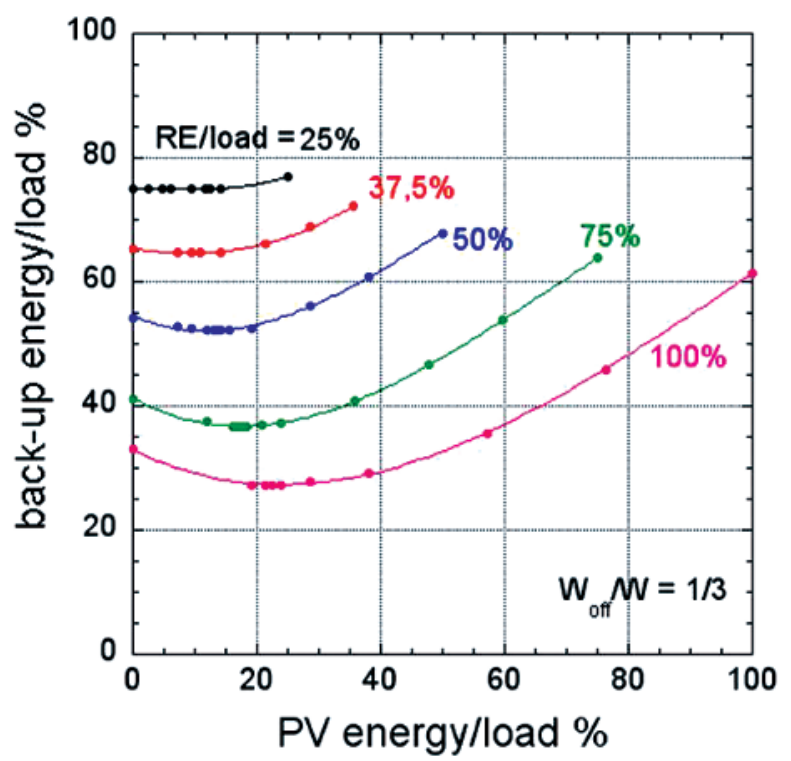

Fig. 12. - The ratio of the back-up energy to the annual reduced electricity demand is plotted against the energy contribution of the PV system, also normalized to the reduced load. The parameter of the curves is the ratio of the energy delivered by the RE normalized against the reduced load. The offshore wind energy is assumed to be $1 / 3$ of the total wind contribution.

Table IV shows the key parameters for the case that RE matches the reduced annual electricity production (562 TWh) under the optimized conditions of minimal back-up need. Onshore wind produces $2 / 3$ of the total wind production in the case considered. Given is the power of each of the systems along with the energy it produces. As the REs do not match the load for each of the time points, $153 \mathrm{TWh}$ have to be delivered by the back-up system (being equal to the surplus energy). The necessary installed power for this purpose is $84 \mathrm{GW}$.

TABLE IV. - Key data for the case that the RE systems produce under the optimal mix conditions the amount of energy corresponding to the demand ("equal energy case").

\begin{tabular}{|l|l|l|}
\hline & Power $(\mathrm{GW})$ & Energy (TWh) \\
\hline Wind onshore & 191 & 294 \\
\hline Wind offshore & 44 & 147 \\
\hline PV & 99 & 121 \\
\hline Back-up system & 84 & 153 \\
\hline Surplus & & 153 \\
\hline Directly used RE energy & & 409 \\
\hline
\end{tabular}




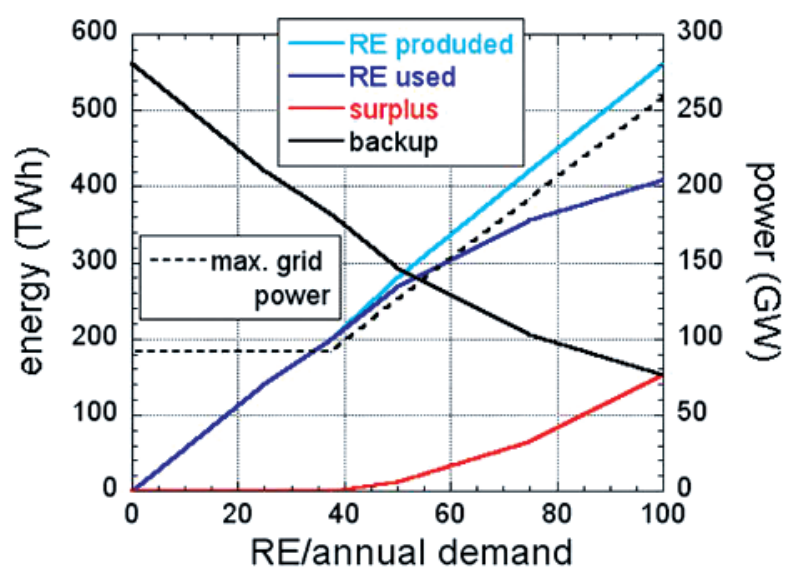

Fig. 13. - The various energies involved and the maximal grid power versus the annual energy from renewable sources normalized to the annual demand (RE share) for the optimal mix case.

Figure 13 shows the energies involved in meeting the annual demand - the one produced by RE, the directly used one, the surplus energy, and the residual energy of the back-up system. Shown is also the maximal grid power. The results are obtained under optimal mix conditions. The directly used RE energy (dark blue curve) increases non-linearly indicating — like in fig. 11 b) for the individual supply techniques — that $\mathrm{RE}$ as considered here will not meet the demand completely. The red curve in fig. 13 represents the surplus power. Surplus power starts playing a role beyond about $40 \%$ of $\mathrm{RE}$ share. The dotted curve is the dispatched power. The maximal power into the grid is $260 \mathrm{GW}$ and is determined by the RE alone. The loading of the grid by the back-up systems does, of course, not affect its maximal loading capacity. The back-up power, which is not plotted, decreases slightly from $92 \mathrm{GW}$ to $84 \mathrm{GW}$ for the "equal energy case" - an $8 \%$ reduction in installed thermal power capacity. At an installed RE power equal to that of the back-up system (equal to the presently installed power system), the RE deliver $25-30 \%$ of the annual demand. A distinct difference in supply characteristics happens for RE shares $>40 \%$ with a pronounced increase in surplus energy and in the power to the grid.

The crosses plotted in fig. 11 a) represent the key data in RE power and energy for the optimal mix case.

The major challenge for the back-up power system is the reduction of the full load hours with increasing RE share. In fig. 14, the capacity factor is plotted against the $\mathrm{RE}$ share. It continuously decreases with increasing $\mathrm{RE}$ contribution. If the $\mathrm{RE}$ are considered individually the capacity factors of the back-up system are larger than in the optimal mix case (see table III). Below a capacity factor of about 0.5, the economic operation of power plants, which were in use under base-load conditions in the past, might become critical. The corresponding RE share for this to happen is around $40 \%$. 


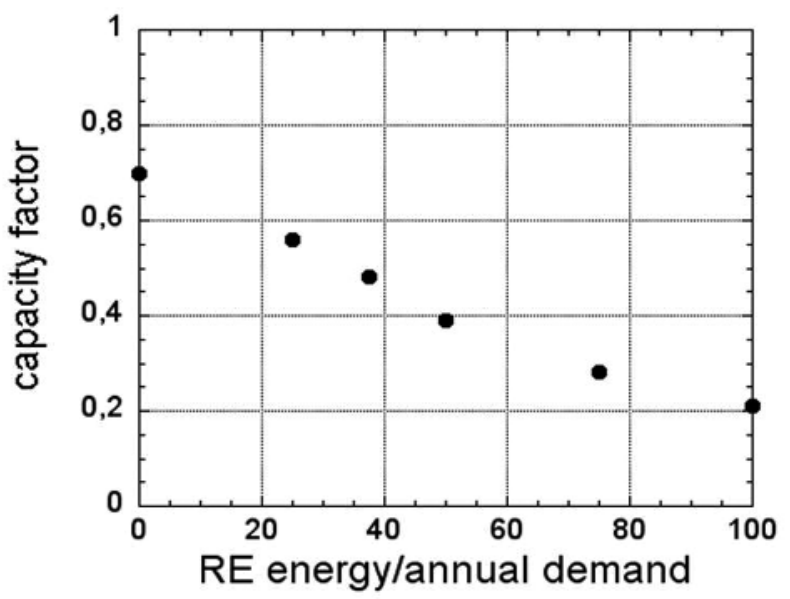

Fig. 14. - Capacity factor against the RE energy share for the back-up system.

The optimal mix case is not suggested here as a development scenario. This is not possible under the present deployment strategy in Germany and may not be possible at all. It rather serves as a reference case to assess and qualify alternatives.

\section{5. - Temporal characteristics of power loading to the grid}

The historic situation is characterized by power delivery by demand with controllable power plants categorized in base, medium and peak loads. The dynamics of the power system was determined by the periodic and rather predictable variation of the load. With increasing stochastic contributions both amplitude and response change and are now governed by the temporal characteristics of the fluctuating sources (see fig. 9). A detailed account of the consequences on the conventional power plants in Germany is given in ref. [3].

The histogram shown in fig. 15 plots the power steps occurring with onshore wind and compares it with offshore wind, PV and the optimal mix case as defined in sect. 4. The "equal energy case" is considered for each of the scenarios. The distributions of the three RE forms differ quite substantially with offshore wind producing the largest number of power steps beyond $2.5 \mathrm{GW}$. Like offshore wind, PV produces high power increments within $15 \mathrm{~min}$ at high power levels of $10 \mathrm{GW}$ and beyond. This corresponds to about half of the day-night cycle of the load but occurring within $15 \mathrm{~min}$. A grid is required with the technical capability to handle such extraordinary events. This dynamics implies that e.g. thirty $300 \mathrm{MW}$ G\&D power stations are cycled from 0 to full power in this period. The consequence would be that many of Germany's thermal power stations act synchronously.

The benefit of the optimal mix is obvious from fig. 15. The power step values are close to those of onshore wind electricity. In all cases, however, the power increments beyond $4.5 \mathrm{GW}$ are distinctively larger than the load alone would demand. 


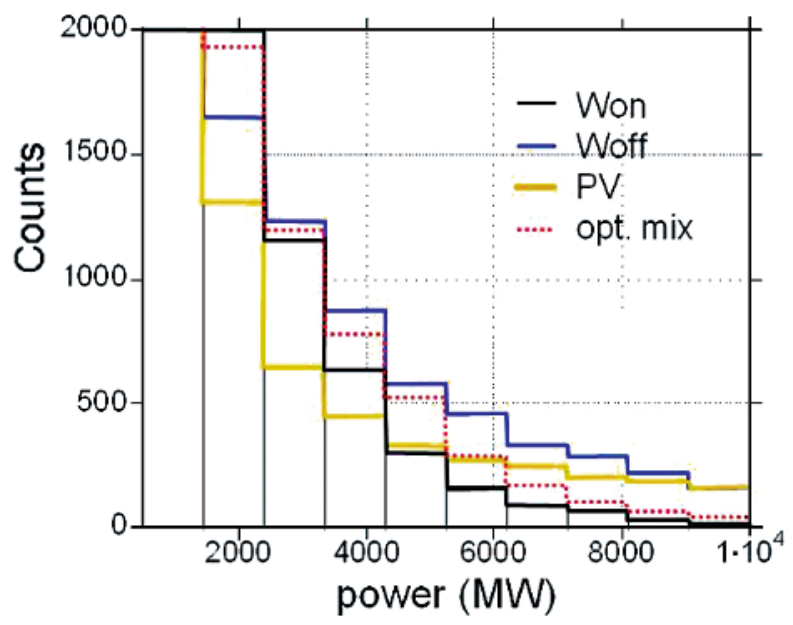

Fig. 15. - Histogram of the power levels for the "equal energy case" with on- and offshore wind, PV and for the conditions of the "optimal mix case".

We have seen that with increasing RE share the capacity factor of the back-up system drops. The periods become longer where the back-up system is not in operation. It can be expected that the number of power cycles for the back-up system therefore decreases with increasing RE contribution. The number of cycles above $1 \mathrm{GW}$ power increment is plotted in fig. 16 for onshore wind with different shares and for offshore wind, PV and the optimal mix case for the $100 \%$ "equal energy case". The cases $|\Delta P|<\mathrm{GW}$ are excluded to separate the frequent small power steps from the critical excursions of interest here.

The distribution between positive and negative power increments is rather symmetric. As expected, the number of power switches drops toward high fractions of onshore wind. The maximum is at about an onshore power fraction of $60 \%$ with nearly 14000 bipolar large power cycles in a year. This goes nearly a factor of two beyond the number of equivalent cycles of the load. The consequence is a much stronger operational demand for the back-up system and represents a challenge to its technical integrity specifically for the larger power excursions necessitating a nearly coherent response of the back-up system. Some of the technical consequences are analysed in ref. [4].

\section{6. - Storage}

Storage would allow to use the surplus power and to ultimately replace the thermal technology of the back-up system achieving thus completely $\mathrm{CO}_{2}$-free electricity supply and would allow smoothing the fluctuations on RE electricity production. No specific storage technology is assumed here.

6'1. Long-term storage. - In the following, we investigate the external conditions for large-scale electricity storage, which would serve a complete annual cycle. The storage 


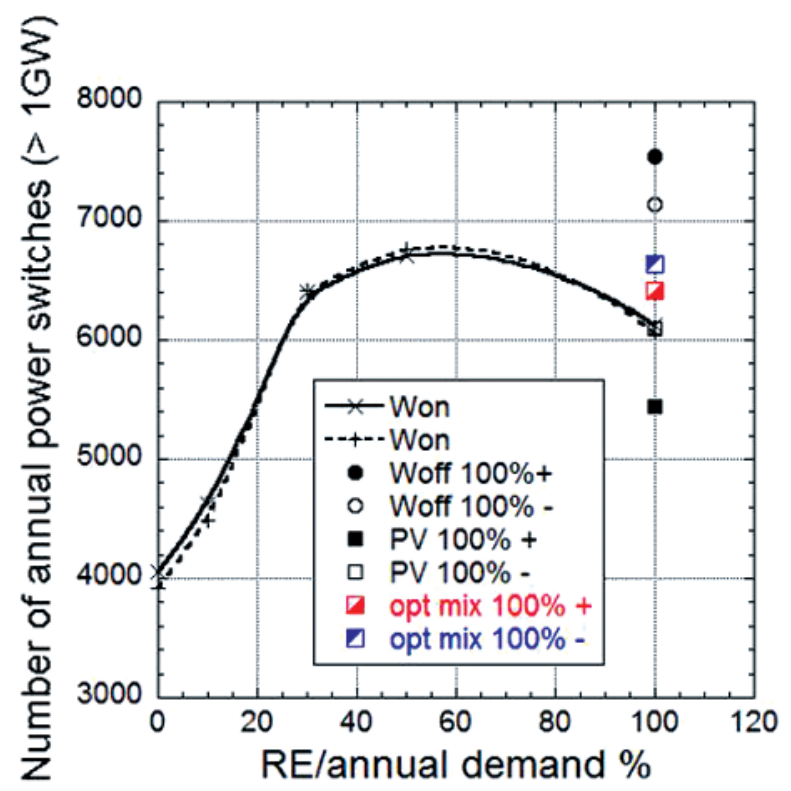

Fig. 16. - The number of power switches of the back-up system $>1 \mathrm{GW}$ are plotted against the annual RE normalized against the annual demand. The results for both positive and negative excursions are shown. For onshore wind, the continuous development from 0 to $100 \% \mathrm{RE}$ contribution to the load is plotted; for the other cases (offshore, PV and the optimal mix case) only the results of the $100 \%$ ("equal energy") cases are given. The solid curve is a guide to the eye for positive and the dashed curve for negative $W_{\text {on }}$ power increments.

parameters are developed first from the characteristics of the three types of sources assumed - on- and offshore wind or PV, respectively. At first, we discuss each source type separately. A condition for a long-term storage system is that its variation is periodic. As we consider one year, the storage conditions at the end of the year have to be the same as at the beginning. Under idealized model assumptions, we fix the initial storage level so that during the year, the complete storage capacity will be used.

Figure 17 shows the variation of the storage level over the year separately for onshore and offshore wind and PV. The "equal energy case" is considered because in this case the surplus energy (to be stored) equals the back-up energy (to be substituted). For the wind cases, the storage level has the tendency to increase in the first months of the year. The storage minimum is reached in August. For PV a larger storage has to be provided because it first empties in the first months till the minimum is reached in mid-March. In the months following March the storage steadily fills with the filling maximum in September-October. The PV storage follows a sinusoidal curve like the solar radiation, however $90^{\circ}$ out of phase.

The red curve in fig. 17 depicts the "optimal mix case" presented in sect. 4. The required storage is strongly reduced with two filling minima in February-March and in August. 


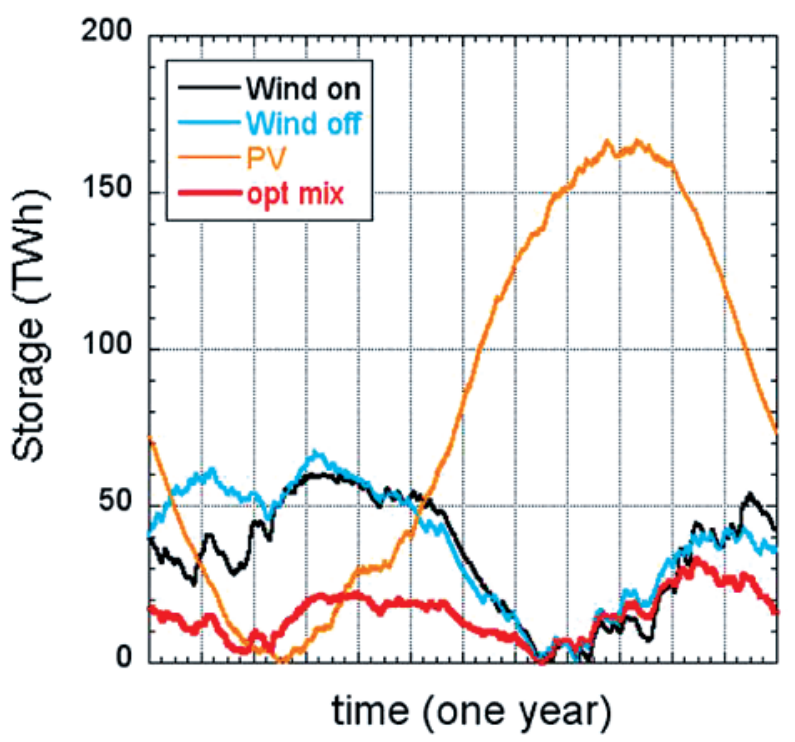

Fig. 17. - The variation of the storage loading with time through the year for the 4 cases considered.

Table V summarises the key parameters of the long-term storage system. PV requires by far the largest storage. Again, the benefit of the optimal mix is evident requiring the smallest capacity. The seasonal differences in input add up rather favourably in this case and reduce the size of storage. The maximal discharging power values (negative) are rather similar for the four cases and they are at the level of the back-up system to be replaced. The charging power levels (positive) are high and vary strongly, depending on the type of source. The maximal power is required, however, for shorter periods only. The figures in brackets in table $\mathrm{V}$ denote the periods where the power is above $100 \mathrm{GW}$. The smallest seasonal storage with a capacity of $33 \mathrm{TWh}$ - as required for the optimal mix case - surpasses the one presently available in Germany by a factor of 500. Such a storage cannot be realised irrespective of the technology employed. Seasonal storage in a closed German system does not seem possible.

TABLE V. - Storage capacity and maximal storage power for the 4 cases considered under the conditions of the "equal energy/optimal mix case"; positive: charging; negative: dispatching; see fig. 17. The respective period for the power $>100 \mathrm{GW}$ is given in brackets.

\begin{tabular}{|l|l|l|}
\hline & Storage energy $(\mathrm{TWh})$ & Maximal storage power $(\mathrm{GW})$ \\
\hline Onshore wind & 60 & $+296,-83$ (1 month) \\
\hline Offshore wind & 67 & $+123,-87$ (24 days) \\
\hline PV & 166 & $+397,-92$ (two months $)$ \\
\hline Optimal mix & 33 & $+179,-85$ (11 days) \\
\hline
\end{tabular}




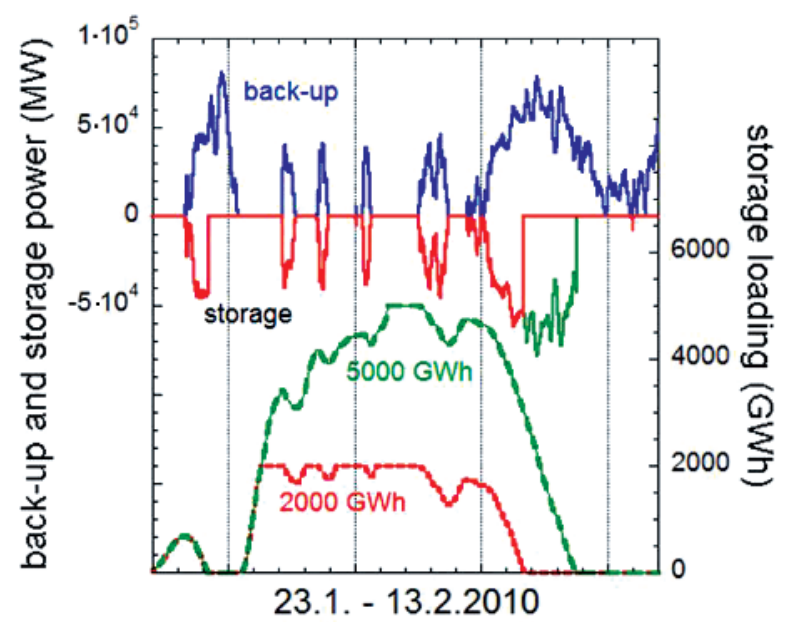

Fig. 18. - For the period shown, the needed back-up power is plotted without storage for the standard "equal energy/optimal mix case". The negative values show the storage power for two cases, which differ in storage capacity, 2000 and $5000 \mathrm{GWh}$, respectively. The right ordinate shows the storage loading for the two capacities considered (lower traces).

6. 2 . Short-term storage. - In the following we investigate continuous operation of the storage - loading whenever surplus power is available up to a specified storage capacity and discharging whenever the RE delivery is insufficient till the storage is empty or a reloading period starts. Figure 18 shows for the period Jan. 23 till Feb. 13 first the time traces of the back-up power in a system without storage and then the storage power (plotted negatively) for two storage capacities -2 and $5 \mathrm{TWh}$. Considered again is the "equal-energy case". Also, the storage loadings (lower curves) are shown. This diagram serves to elucidate the operation of the storage and its impact on the dynamics of the back-up power system. When the storage is sufficiently filled, the power from the storage matches (and substitutes) the back-up power. The larger the storage capacity, the shorter are the remaining periods needing back-up support. When the storage is empty its power becomes zero and this happens for the larger capacity storage at a later time. When the storage is full, surplus power is not fully used and available for other means.

Figure 19 exemplifies the operation with an assumed 200 GWh storage (about 4 times the presently installed storage capacity in Germany) in the limit that the energy produced by $\mathrm{RE}$ is equal to the demand ("equal energy case") and for the optimal mix. Shown is one week in summer (28.6.-4.7.) and one in winter (21.2.-27.2.). The weeks start with Monday. In summer, the RE electricity is produced by PV systems and is fairly periodic. The surplus power fills the storage, which then delivers the power mostly in the following night. In the winter week, the power is delivered primarily by wind. The surplus power is generally too large to be accommodated by the storage system. Storage stops in the middle of the period with available surplus power because of capacity limitation. 

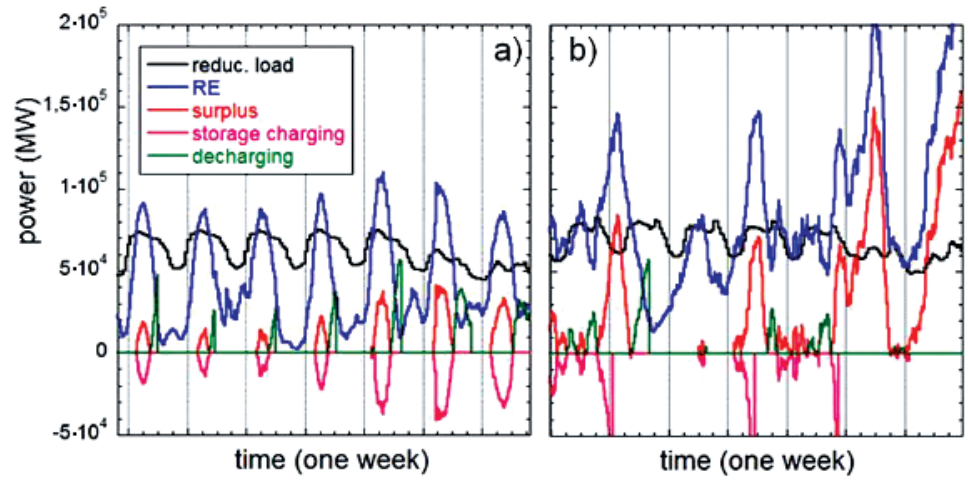

Fig. 19. - For one week in summer (a) and one in winter (b) the reduced load is shown for the standard "equal energy case" along with the power of the RE, the surplus energy, the power from charging (negative) and discharging the $200 \mathrm{GWh}$ storage.

Discharging of the storage is erratic and is interrupted for longer periods in phases of large RE power with sufficient surplus production at a full storage or in periods of an empty storage without surplus production. The necessary back-up energy reduces from annually $153 \mathrm{TWh}$ to $128 \mathrm{TWh}$ in this case whereas the back-up power does not change.

Figure 20 shows the duration curve, now of the storage system of different capacities starting from the reduced load and the residual load without storage in the limit of

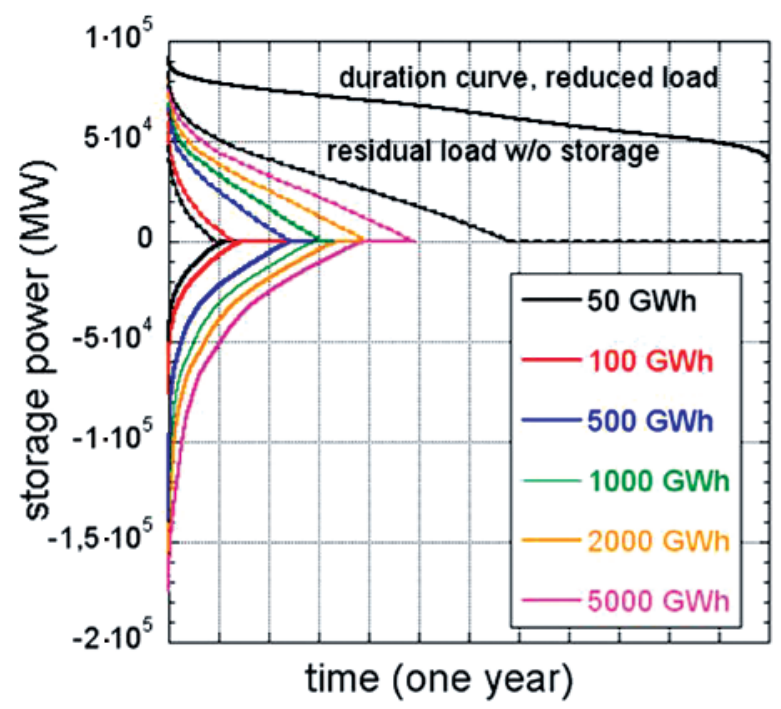

Fig. 20. - Annual duration curves of the storage power starting with the reduced load for various storage capacities. Both the charging and discharging (negative) periods are plotted. The calculations are done for the standard "equal energy, optimal mix case". Shown is also the residual load (with the RE contribution subtracted from the reduced load) without storage. 
TABLE VI. - The full-load hours (fh) and the capacity factors for storage and back-up system for the cases plotted in fig. 20.

\begin{tabular}{|l|l|l|l|l|}
\hline $\begin{array}{l}\text { Storage capacity } \\
(\mathrm{GWh})\end{array}$ & $\begin{array}{l}\text { flh storage } \\
(\mathrm{h})\end{array}$ & Capacity factor storage & $\begin{array}{l}\text { flh back-up system } \\
(\mathrm{h})\end{array}$ & $\begin{array}{l}\text { Capacity factor } \\
\text { back-up system }\end{array}$ \\
\hline 50 & 177 & 0.02 & 1711 & 0.195 \\
\hline 100 & 241 & 0.027 & 1636 & 0.187 \\
\hline 500 & 541 & 0.062 & 1343 & 0.153 \\
\hline 1000 & 768 & 0.088 & 1140 & 0.130 \\
\hline 2000 & 957 & 0.109 & 899 & 0.103 \\
\hline 5000 & 1244 & 0.142 & 603 & 0.069 \\
\hline
\end{tabular}

the "equal energy/optimal mix case". The positive branches show the discharging, the negative ones the charging periods. At low capacity, the charging periods are slightly longer than the discharging ones. This turns around for large storage capacities, which are able to accommodate large power peaks shortening the charging periods.

Table VI describes the use of storage and that of the back-up system in terms of full-load hours or capacity factors, respectively. These values address the question of economic use of the infrastructure. Full-load hours and capacity factors increase with storage capacity whereas those of the back-up system decrease. For the full range of storage capacity assumed the economic operation of storage and back-up system can be questioned. The lowest storage capacity of $50 \mathrm{GWh}$ corresponds to the one presently available in Germany. This storage operates under economic conditions predominantly used to meet peak-load conditions. Here, however, we consider exclusively the conditions for surplus power storage.

The simplest, however uneconomic way to avoid surplus power is to stop dispatching RE into the grid. This may be technically more easily possible with wind converters than with PV systems. We consider the "equal energy, optimal mix case". The sequence of interventions starts with reducing onshore wind power and continues — if necessary — via offshore wind to PV. If surplus power is available, first onshore wind is correspondingly reduced. If this is not sufficient, offshore wind is also reduced. The full-load hours of onshore wind drop from $1545 \mathrm{~h}$ to $828 \mathrm{~h}$, those of offshore drop from $3385 \mathrm{~h}$ to $3117 \mathrm{~h}$ whereas there is no need to also reduce PV — which represents anyway the technically most complex form of intervention. As a consequence the peak onshore wind power values $>100 \mathrm{GW}$ are avoided; the system use is, however, practically halved with corresponding economic consequences.

\section{7. - Scenario characteristics of a probable upper limit: $40 \%$ energy from RE sources}

If a total coverage of the German electricity demand by RE were hardly possible, what could realistically be envisaged and what are the limiting elements? There are several 
TABLE VII. - Key-parameters describing the power $(G W)$ and annual energy values for the case that $40 \%$ of the annual electricity demand are covered by RE under optimal mix conditions. The increase with respect to the situation in 2011 is also given. The values in brackets include the correction of the maximal power values in the data base to the actually installed powers (see fig. 1).

\begin{tabular}{|l|l|l|l|l|}
\hline Technlogy & $\begin{array}{l}\text { Installed } \\
\text { power } \\
(\mathrm{GW})\end{array}$ & $\begin{array}{l}\text { Annually } \\
\text { produced energy } \\
(\mathrm{TWh})\end{array}$ & $\begin{array}{l}\text { Increase/decrease } \\
\text { in power compared } \\
\text { to 2011 }\end{array}$ & $\begin{array}{l}\text { flh } \\
\text { (h) }\end{array}$ \\
\hline Reduced load & 91 & 562 & & 6116 \\
\hline Onshore wind & $69(82)$ & 106 & $\times 2.4(2.8)$ & 1545 \\
\hline Offshore wind & 16 & 53 & $\times \sim 80$ & 3384 \\
\hline PV & $55(84)$ & 66 & $\times 2.2(3.4)$ & 1217 \\
\hline Back-up system & 86 & 340 & $-5.5 \%$ & 3974 \\
\hline Surplus power & 35 & 3 & & 77 \\
\hline Storage & $35($ charging) & 2.7 & $\times 7.3$ & \\
\hline Storage & 47 (discharging) & & & \\
\hline Maximal grid power & 101 & & & \\
\hline
\end{tabular}

reasons for limitations - technical problems like grid stability or conflicting technical solutions like in Denmark between prioritized RE feed-in and CHP production by thermal power stations [5]. Here we assume that the limitations are given by an excessive level of surplus power and the short-term power increments, which can still be handled by the size of the storage needed, by the need to operate a back-up system economically and by the option to limit grid expansion capacity because of costs and its inherent societal complexity. Within these limits, we assume that RE can deliver $40 \%$ of the annual energy demand (see also fig. 13) and that Germany has available a storage capacity of $200 \mathrm{GWh}$. The key-data of such an electricity infrastructure are given in table VII.

In this setting, the RE is used well. Only $3 \mathrm{TWh}$ are produced as surplus energy and from this, $2.7 \mathrm{TWh}$ are dispatched via the storage. Only $300 \mathrm{GWh}$ (representing an economic value of several Mill $€$ ) have to be exported or avoided by temporarily reducing production capacity. The storage uses, therefore, the surplus energy well but at a lowenergy turnaround. Of course, such a storage would not be used for exclusively storing the surplus energy but it would operate like today using the available power and charge and discharge according to the market situation. Still, the problem is evident: The excess power levels reaching up to $35 \mathrm{GW}$ to be handled are too large for simple export; the surplus energy levels on the other hand seem to be too small for economic storage. Even at the assumed RE contribution of $40 \%$, the rational to operate a storage will come from economic considerations and less from the intension to maximally use surplus energy and thus reduce $\mathrm{CO}_{2}$ emission. A higher $\mathrm{RE}$ fraction will increase the surplus power but will risk the economic operation of the back-up system without improving much the one of the storage system (see fig. 17). 


\section{8. - Analysis and comments}

The production of electricity with variable sources is not the problem. If a society agrees to the corresponding use of land and finances the necessary investments the electricity to be produced can be increased proportional to the allocated area $\left({ }^{4}\right)$.

The following actual problems and issues in the large-scale use of $\mathrm{RE}$ have been identified:

- RE requires large power installations. The necessary investments can be reduced by a proper mix of wind and PV power. For the "optimal mix, equal energy" case, the energy, which has to be delivered by the back-up system and the associated $\mathrm{CO}_{2}$ output are minimized. $84 \mathrm{GW}$ installed power contributes with $153 \mathrm{GWh}$.

With the assumption of this paper (no electricity import, no use of bio-mass apart from waste), variable sources cannot meet the electricity demand alone. By increasing their share, the directly used power saturates well below the demand whereas the surplus power rises steeply.

Already at lower RE shares, close to and above $40 \%$ of the energy demand, the surplus power reaches a level, which can be handled neither by reasonable technology nor by cross-border trade. It also cannot be simply wasted because of its high economic value. The systems - preferably wind turbines - have to be throttled in this case accepting economic losses. Germany, though leading in the installation of RE systems, is still below any of these critical limits (see fig. 12 a).

$\mathrm{PV}$ is the most ineffective RE supply form. It requires the largest installed power per delivered energy unit and it causes extreme surplus power peaks. This negative aspect adds to those, which are well known and documented: PV has the highest material use, the highest primary energy use and the highest costs per unit of electricity produced [6].

- Without proper storage, the RE use cannot prevent the need for a back-up system of conventional power plants. The nominal power of the back-up system has to remain high and is hardly reduced by the addition of RE power. Its energy supply, however, which is the economic factor, decreases with increasing RE share.

The back-up system has to be operated under strongly varying conditions. The number of thermal cycles increases because the system dynamics is no longer determined by that of the demand rather by that of the supply.

- Large storage capacity both in energy and power handling capability is necessary replacing the back-up system of thermal power stations and thus optimizing the

$\left({ }^{4}\right)$ We have not considered restrictions in development zones for RE systems as they are presently defined in Germany. These zones are subject to political decisions and are expanding with time. 
$\mathrm{CO}_{2}$ balance. A notable effect on reducing the size of the back-up supply requires a storage, which is far beyond any chances of realization.

- The use of variable sources with short full-load hours forces the other components of the supply system operated during the gaps also to low-capacity factors. Specifically, the increase in power installation causes a corresponding decrease of the full-load hours of the back-up system. The storage, when seen exclusively as a means to store surplus power, is subject to the same shortcomings causing lowcapacity factors. The complete supply system comprises of components, which are not operated adequately in an economic sense.

Some of these issues are ameliorated by supra-national girds because both load and variable production are smoothed. It can be doubted that this will happen in near future. Energy policies in Europe are considered national sovereignty. Also the enforced deployment of RE in Germany, which - when continued with the present development speed - will produce tremendous amounts of surplus, will limit the expansion options of its neighbours because most conspicuously, surplus will be further increased.

As a consequence, the development of alternative electricity supply forms is still of highest relevance and may become even more urgent after a realistic view into the capabilities and the limits of REs. Because of the limitations and shortcomings in their use, the most obvious question will be whether and how an electricity system based on variable sources can be improved and supplemented. This will be a question classically posed to research and engineering because these disciplines have found the ways in the past to liberate mankind from the imponderabilities and perils of nature.

$* * *$

The author is grateful to his colleagues from the Board of the Energy Group of the European Physical Society for stimulating discussions. The clearance of the FINO data by the BMU and the Projektträger Jülich is gratefully acknowledged.

\section{APPENDix A.}

\section{Construction of the data set}

The following source data were used.

The electricity demand (load) was obtained from Tennet [7] with 15 min resolution and from ENTSO-E [8] with $1 \mathrm{~h}$ resolution. The more representative ENTSO-E data were taken. The ENTSO-E data were scaled to deliver the net electricity production of 588 TWh in 2010 (see table I) [9]. Thus, the demands both from the high-voltage and the lower-voltage grids are included.

The onshore wind data are obtained from 50Hertz [10] with 15 min resolution. In order to represent the total wind electricity in 2010 , the data were scaled to the totally harvested wind electricity of Germany of 35.3 TWh [9]. In order to check whether this spatial extrapolation is justified the $50 \mathrm{Hertz}$ onshore wind data are correlated with data obtained from TransnetBW [11] representing the wind pattern over Baden-Württemberg. 
The correlation coefficient $R=0.48$. The correlation function has a distinct maximum with a delay of $2 \mathrm{~h}$.

Offshore wind is not yet available in Germany to the extent that one could apply the same procedure as for onshore wind. The offshore data used were constructed from wind velocity data $v_{\mathrm{w}}$ obtained from FINO3 [12]. Data were taken from the sensor at $100 \mathrm{~m}$ height pointing in $345^{\circ}$ direction $\left({ }^{5}\right)$. The offshore wind power is given by the cubic relation: $P=\alpha v_{\mathrm{w}}{ }^{3}$. In order to get verified power values the data from the first successful operation of the north-sea test-field Alpha Ventus wind park [13] were used. The $2 \times 6$ wind turbines with a nominal power of $5 \mathrm{MW}$ each worked from October 2010 to June 2011 without interruption and produced $190 \mathrm{GWh}$. For the determination of $\alpha$ the wind velocity data were matched to the operational conditions of the wind turbines. The power was set to 0 for wind velocities $v_{\mathrm{w}}<3.5 \mathrm{~m} / \mathrm{s}$ (cut-in velocity) or $v_{\mathrm{w}}>30 \mathrm{~m} / \mathrm{s}$ (which was not reached in the considered data sample); $P$ was assumed to scale according to the above cubic relation between $3.5 \mathrm{~m} / \mathrm{s}$ and $14.5 \mathrm{~m} / \mathrm{s}$ and to be constant at the maximal power $\left(5 \mathrm{MW}\right.$ ) for 14.5 (rated velocity) $<v_{\mathrm{w}}<30 \mathrm{~m} / \mathrm{s}$ (cutout velocity). It is problematic to take point data as representatives for a turbulent field where, in the area, specifically the peaks average out to a certain extent. In case of offshore wind, the peaks are removed by the maximal power setting of the turbines. Therefore, this way of constructing the data seems justified.

Again, as a means of control, the FINO3 velocity data and the onshore wind power values were correlated $\left(v_{\mathrm{w}}{ }^{3}\right.$ with $\left.P_{\mathrm{on}}\right)$. The correlation coefficient $R=0.46$ indicating a weak but distinct relationship of the data as can be expected facing the long-range nature of the wind pattern over Germany (50Hertz region) and the German Bay region. The correlation is between a point value (FINO3 velocity) and a field average value $\left(P_{\text {on }}\right)$. The correlation function has a maximum and decreases for larger time shifts between the data. For comparison, the offshore wind data were also correlated to the PV data. Of course, no correlation is expected. The correlation coefficient is found to be $R=0.09$.

The photovoltaic data were obtained from $50 \mathrm{Hertz}$ in 15 min increments [10]. Like in the other cases, they were scaled to the photovoltaic energy harvested in 2010 of 11.8 TWh. A further correction was necessary because of the strong development of PV systems in Germany in 2010 growing from $9.9 \mathrm{GW}$ installed power at the end of 2009 to $16.8 \mathrm{GW}$ (up to $17.3 \mathrm{GW}$ can be found in the literature) a year later. As we assume constant installed PV power for the scenarios to be analysed in this study, the 2010 data were corrected assuming a linear growth of installed power in 2010 (which differs from the actual growth curve, which is ignored). The corrected PV data set would have delivered 13.4 TWh at a constant installed power of $16.8 \mathrm{GW}$.

In this manner, a data base for the load, $W_{\text {on }}, W_{\text {off }}$ and PV power is obtained for 35040 time points with a resolution of $15 \mathrm{~min}$. The ENTSO-E load data with $1 \mathrm{~h}$ time steps are kept constant over the $15 \mathrm{~min}$ time grid. The comparison with the regionally limited Tennet load data with $15 \mathrm{~min}$ resolution shows that no significant error is introduced by smoothing the load. Anyway, the major dynamics in the data base is introduced by the RE supply forms. For the temporal response studies of sect. 5, however, the better time-resolved Tennet data were used.

$\left({ }^{5}\right)$ A few gaps in the data were filled with data from the sensor at $106 \mathrm{~m}$ height. The missing data of the 1st week in January 2010 were replaced by data from January 2011 of the same week. The velocity data are provided in $10 \mathrm{~min}$ increments. For a synchronized data base ordered in quarter-hour steps, the data at the full and the half hour could directly be used. The data at $15 \mathrm{~min}$ and $45 \mathrm{~min}$ were obtained by interpolation. 


\section{REFERENCES}

[1] For a general readership the book "Energy Survival Guide" by Jo Hermans gives a short but still broad introduction into many energy-related issues; "Sustainable Energy - without the hot air" by MacKaye is highly recommended for an interested readership specifically as it is also available at the internet (http://www.withouthotair.com/); specialised interests are best served by the Landolt-Börnstein series on Energy Technologies, volumes VIII/3A, B, and C. As we concentrate on wind and photovoltaic energies, the reader may turn to "Introduction to Wind Energy Systems" by H.-J. Wagner and J. Mathur and to "Physics of Solar Cells" by P. Würfel introducing into the physics background of these technologies. A general overview over the German electricity supply is provided by the study of the "Arbeitskreis Energie" of the German Physical Society: "Electricity: The key to a sustainable and climatecompatible energy system": www.dpg-physik.de/ veroeffentlichung/broschueren/studien/energy_2011.pdf.

[2] www.ise.fraunhofer.de.

[3] Ziems CH. et al., "Effects of fluctuating wind power and photovoltaic production to the controlability and thermodynamic behaviour of conventional power plants in Germany". VGB PowerTech Study, Uni Rostock.

[4] Weber H. et al., "Technical Framework Conditions to Integrate High Intermittent Renewable Energy Feed-in in Germany", Wind Energy Management, ISBN: 978-953-307336-1, InTech, 2011. Available from: http://www.intechopen.com/books/windenergymanagement/technical-framework-conditions-to-integrate-high-intermittentrenewable-energy-feed-inin-germany.

[5] Sharman H., "Wind Energy - the case of Denmark", CEPOS, Sept. 2009 (www. cepos.dk).

[6] Marheineke T., "Lebenszyklusanalyse fossiler, nuklearer und regenerativer Stromerzeugungstechniken", IER Forschungsbericht, Band 87, 2002.

[7] www.tennettso.de/site/Transparenz/veroeffentlichungen.

[8] www.entsoe-eu.

[9] www.bmwi.de.

[10] www.50hertz.com.

[11] www.transnetbw.de/kennzahlen/erneuerbare-energien/windeinspeisung/.

[12] www.fino-offshore.de.

[13] www.alpha-ventus.de. 